\title{
Transparent Electrode Materials for Solar Cells
}

\author{
Jan Meiss ${ }^{a}$, Christian L. Uhrich ${ }^{b}$, Karsten Fehse $^{a}$, Steffen Pfuetzner ${ }^{a}$, Moritz K. Riede $^{a}$, \\ and Karl Leo ${ }^{a}$ \\ ${ }^{a}$ Institut für Angewandte Photophysik, Technische Universität Dresden, \\ George-Bähr-Straße 1, 01062 Dresden, Germany; http://www.iapp.de \\ ${ }^{b}$ heliatek GmbH, Liebigstraße 26, 01187 Dresden, Germany
}

\begin{abstract}
Alternatives for replacing the expensive ITO are explored and Poly(ethylene dioxythiophene):polystyrene sulfonate (PEDOT:PSS) is introduced as one possibility. We present the first small-molecule organic solar cells employing only PEDOT:PSS as transparent electrode. Solar cells on glass and on flexible plastic foil were prepared, using a p-doped hole transporting material, zinc phthalocyanine (ZnPc) and $\mathrm{C}_{60}$ as donoracceptor heterojunction, and an exciton blocking layer. Different methods to structure the PEDOT:PSS electrodes were investigated and are presented. As proof of principle, non-optimized prototype cells with efficiencies of over $0.7 \%$ on glass and $0.9 \%$ on flexible plastic foil substrate were obtained.
\end{abstract}

Keywords: PEDOT:PSS, solar cell, ITO, transparent electrode, small-molecule, conductive polymer

\section{INTRODUCTION}

In the last years, rising oil prices, the discussion about peak oil, increasing energy consumption especially in emerging nations and increasing public attention about climate change ${ }^{1}$ have obtained attention. All of these issues demand innovative solutions in form of sustainable, regenerative, environmental-friendly means of energy generation.

This resulted in a dramatical increase of research and development, but also industrial production in the field of photovoltaics. While crystalline silicon solar cells are a well-established field and copper indium gallium selenide (CIGS) technology nearing large-scale production, one is still confronted with the argument that inorganic photovoltaics are too expensive per $\mathrm{kWh}$. Hence, on the mass market solar energy is currently not competitive with fossil fuels.

Organic solar cells are a promising approach in the long term to reduce costs of photovoltaic energy below both inorganic photovoltaics and fossil fuels. As a result, one finds an exponential increase of research and peer-reviewed publications in this emerging field. There are four main approaches, the dye-sensitized or Grätzel solar cells, ${ }^{3}$ polymer-based solar cells, ${ }^{5}$ inorganic-organic hybrid solar cells ${ }^{4}$ usually created by wet chemical processes, and small-molecule organic solar cells (SM-OSCs), the focus of the current work.

After the breakthrough of Tang $^{6}$ in 1986, who employed a heterojunction of of copper phthalocyanine and a perylene derivative, new concepts like bulk heterojunctions, doping of organic molecules, ${ }^{7}$ or $\mathrm{p}$-i-n structures with dedicated charge carrier transport layers ${ }^{8}$ have resulted in efficiencies over $5 \%{ }^{9}$

Small-molecule organic solar cells produced via vacuum-evaporation have the potential for a very costefficient, light-weight, large-area technology, possibly also on flexible, non-planar substrates. A typical structure of this type of solar cell can be seen in Fig.1; the stack is deposited on glass or pastic foil covered with a transparent, conductive electrode. The active layers consist of (p-doped) hole transporter (HTL), absorber (e.g. bulk heterojunction) and (n-doped) electron transporter (ETL), and possibly an exciton blocking layer (EBL). On top of the organic layers, a reflecting back contact (typically Al) is deposited.

Further author information:

J. Meiss, e-mail: jan.meiss@iapp.de, Phone: +49-(0)351-463-38773

K. Leo, e-mail: karl.leo@iapp.de

Photonics for Solar Energy Systems II, edited by Andreas Gombert

Proc. of SPIE Vol. 7002, 700210, (2008) - 0277-786X/08/\$18 - doi: 10.1117/12.781275

Proc. of SPIE Vol. 7002 700210-1 


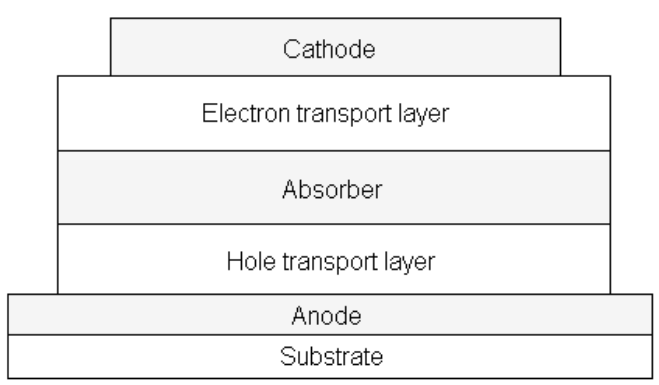

Figure 1. Schematic of a p-i-n type solar cell structure. The anode is typically a transparent conductive oxide, the cathode a metal contact. The hole transport layer is p- and the electron transport layer n-doped.

\section{TRANSPARENT CONTACTING MATERIALS}

\subsection{ITO}

One issue associated with polymer- and SM-OSCs is based on the fact that the standard transparent contact material on the substrate is $\mathrm{In}_{2} \mathrm{O}_{3}: \mathrm{Sn}$ (ITO). In the past decade, the price of indium has risen dramatically, and projections suggest that this scarce resource might be depleted within the next decade. Hence, one of the main advantages of organic solar cells, the potentially low price, might be outbalanced by rising transparent conductive oxide (TCO) costs. The price of ITO, its brittleness (an issue for flexible devices) and the possible diffusion of indium into organic materials, are strong arguments for finding alternative transparent electrode materials.

\section{$2.2 \mathrm{ZnO}: \mathrm{Al}$}

One possible alternative to ITO is another transparent conductive oxide (TCO), aluminium-doped zinc oxide ( $\mathrm{ZnO}: \mathrm{Al}$, or often abbreviated AZO). It was shown by Schulze et al. ${ }^{10}$ that $\mathrm{ZnO} \mathrm{Al}$ can be used as hole contact with similar performance. Generally, $\mathrm{ZnO}$ : Al has a similar conductivity as ITO, with resistivities ranging from low $10^{-4} \Omega \mathrm{cm}$ for pulsed laser deposition to low $10^{-3} \Omega \mathrm{cm}$ for magnetron sputtering and transmittance of $80-90 \%$ in the visible. However, $\mathrm{ZnO}$ is chemically instable to acid, somewhat brittle and tends to grow with rough surfaces; additionally, the deposition processes may be harmful to organic materials if deposited on top, e.g. in inverted structures. ${ }^{11}$

\subsection{PEDOT:PSS}

Poly(ethylene dioxythiophene):polystyrene sulfonate (PEDOT:PSS) (Fig.2) is a conductive polymer. Owing to intense research activity in the last years, there are many different formulations of PEDOT available; it can be used as antistatic coating, matrix for carbon nanotube networks, or for better hole transport between ITO and organic materials. ${ }^{12}$ Recently, it was shown that PEDOT:PSS formulations can be used as transparent contact for polymer-based solar cells (combined with a silver grid $^{14}$ or using a novel wrap-through concept ${ }^{13}$ ) and small-molecule based organic light-emitting diodes (OLEDs) where PEDOT:PSS led to better results compared to ITO. ${ }^{15}$

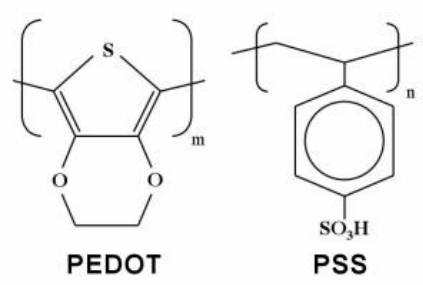

Figure 2. Structure of Poly(ethylene dioxythiophene) (PEDOT) and polystyrene sulfonate (PSS) 
Disadvantages of PEDOT:PSS are its susceptibility to oxygen, $\mathrm{H}_{2} \mathrm{O}$, sodium (from glass substrates) and UV-light. With a conductivity of $500 \mathrm{~S} / \mathrm{cm}$, it still cannot compete with optimized ITO. Another point is that PEDOT is usually applied from a water-based solution via spin-coating, a wet chemical process that is not always compatible to thermal evaporation in UHV, the standard method for creating SM-OSOLs.

Nonetheless, first studies with OLEDs were promising and showed devices with comparable performance to ITO-based counterparts. Hence, the present work aims at a proof of principle that PEDOT:PSS can be applied as anode for SM-OSOLs.

\subsection{Others}

Apart from the aforementioned materials, there are other transparent conductive materials that will just be mentioned briefly. A commonly used TCO is $\mathrm{SnO}_{2}$; it was disregarded in the present study since it requires high substrate temperatures during processing. There is a number of ternary compounds, e.g. $\mathrm{Cd}_{2} \mathrm{SnO}_{4}, \mathrm{CdSnO}_{3}, \mathrm{CdInO}_{4}, \mathrm{Zn}_{2} \mathrm{SnO}_{4}, \mathrm{MgIn}_{2} \mathrm{O}_{4}, \mathrm{CdSb}_{2} \mathrm{O}_{6}, \mathrm{In}_{4} \mathrm{Sn}_{3} \mathrm{O}_{12}$; however, many of these contain indium, cadmium and/or are still in early experimental stages. Another possibility is using thin metal films, where a careful balance between layer morphology, transmission and conductivity has to be maintained. First results with SM-OSOLs show promising potential. ${ }^{16}$

On the organic side, much progress has been made on the field of carbon nanotubes. Already, there are polymer-based solar cells employing this class of material (either as stand-alone electrode ${ }^{17}$ or combined with ITO or a polymer matrix $\left.{ }^{18}\right)$. For SM-OSOLs, carbon nanotubes are difficult to use since typical thicknesses of the complete stack (charge transport and absorber layers) are well below $150 \mathrm{~nm}$, while carbon nanotubes can form a non-uniform, not fully closed layer with protrusions that by far exceed several hundreds of nm, leading to shorts.

\section{EXPERIMENTAL}

This section describes the complete process of first creating a PEDOT:PSS hole conductive layer and then, after structuring, fabricating and characterizing a complete solar cell.

\subsection{PEDOT:PSS Preparation}

The PEDOT:PSS formulation in the current work was BAYTRON PH500 (H. C. Starck) with 5\% of dimethyl sulfoxide (DMSO) added to the aqueous solution. With addition of DMSO, a conductivity increase to 500 $\mathrm{S} / \mathrm{cm}$ was observed. The formulation was used as received. The PEDOT:PSS bottles were kept in the dark in a refrigerator to prevent premature polymerization or degradation. To reduce viscosity, the bottles were removed from the fridge $24 \mathrm{~h}$ prior processing. For some experiments, $10 \mathrm{wt} \%$ of the perfluorinated ionomer Nafion (Sigma-Aldrich) was added to the solution, directly prior to spincoating.

Substrates were 2.54 by $2.54 \mathrm{~cm}^{2}$ (1 square inch) float glass pieces or PET foil. Glass substrates were cleaned by sonicating in Extran, deionized water, acetone, ethanol, and iso-propanol; PET foil substrates were pre-structured with a laser printer (see below) and cleaned with de-ionized water and ethanol. To improve wetting, all substrates were treated in a UV-oxygen plasma-etching system before spincoating. This removed further contamination and led to increased hydrophilicity and lower contact angles of the PEDOT:PSS solution on the substrate and was found essential for uniform and homogeneous films.

The spincoating was performed on a spin coater with 1400-1800 rpm for 30s. Independent of the structuring method, samples were outgassed after spincoating on a hot plate in ambient conditions, at temperatures of $80^{\circ} \mathrm{C}$ (for PET foil) up to $140^{\circ} \mathrm{C}$ (for glass substrates), with durations of typically 20-60 minutes. Purpose of the outgassing was to remove residual water and DMSO from the aqueous solution.

\subsection{PEDOT:PSS Structuring}

To avoid shorts and to get spatially well-defined anode structures, several steps were carried out to structure the uniformly spincoated PEDOT:PSS films before thermal evaporation. This is depicted schematically in Figure 3 and will be explained in the next two sections. 


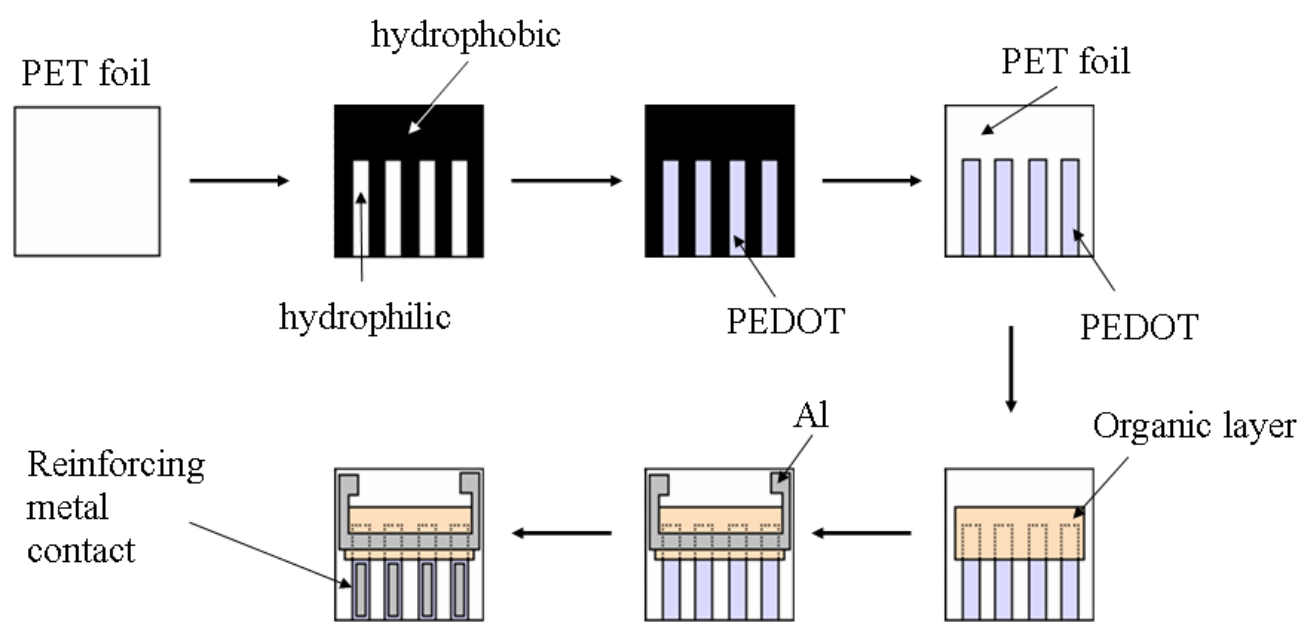

Figure 3. Schematic series of the steps undertaken to structure PEDOT:PSS as anode on PET foil.

\subsubsection{Structuring on glass}

After spincoating on a pre-cleaned, plasma-treated substrate, a uniform film is achieved and afterwards dried as described above. Subsequently, a fresh solution of $10 \mathrm{wt} \%$ polystyrene in toluene is made and stirred until the polystyrene is completely dissolved. The sample is then partially (25\%) dip-coated with dissolved polystyrene and again heated to remove traces of toluene. After drying, the sample is still completely coated with PEDOT:PSS, but 25\% have a transparent, insulating layer on top of the PEDOT:PSS. This layer has been found thick enough to protect the conductive polymer below from shorts, but the transition from polystyrene to PEDOT:PSS below is so smooth and gradual that it can be assumed flat for the thermal evaporation process.

\subsubsection{Structuring on PET foil}

Structuring of PET foil samples is illustrated in Fig. 3. The principle used for this method is that BAYTRON PH 500 ships as aqueous solution, needing a hydrophilic surface for adherence. By plasma cleaning, PET foil can be made sufficiently hydrophilic. Toner, as printed by laser printers, is inherently hydrophobic, repelling the solution. One can use CAD software to print patterned toner structures on transparent foil using standard laser printers (here: HP LaserJet 1320). After the obligatory oxygen-plasma-treatment, PEDOT:PSS adheres only on the transparent, non-printed areas of the foil, while the toner remains uncoated. Following the drying $\left(80^{\circ} \mathrm{C}\right)$, the sample is sonicated in a beaker of toluene for several minutes. This removes the toner, which dissolves in toluene, while the PEDOT:PSS layer still adheres on the foil, resulting in well-defined structures of closed conductive film. In the next step, organic layers (the solar cell stack) can then be deposited, as described below.

\subsection{Evaporation}

The solar cells were fabricated by thermal evaporation in a custom-made UHV multi-chamber system with pressures of $10^{-6}-10^{-8} \mathrm{mbar}$, using shadow masks. Different chambers were used for HTL, absorber, ETL, EBL and metal contact. Doping was performed by co-evaporation of dopant and host; all organic materials were purified by vacuum gradient sublimation at least twice before usage. Typical deposition rates were around $0.5 \AA / \mathrm{s}$. Solar cell stack and used materials are shown in Fig. 4.

Starting with a PEDOT:PSS ground contact, $1 \mathrm{~nm}$ of a proprietary p-type dopant (Novaled AG, Dresden, Germany) was deposited, comparable in performance to the commonly available 2,3,5,6-Tetrafluoro-7,7,8,8tetracyanoquinodimethane (F4-TCNQ) (not shown).

As HTL, p-doped 4,4',4"-tris(1-naphthylphenylamino)-triphenylamine (TNATA) was used with different layer thicknesses $(60 \mathrm{~nm}-100 \mathrm{~nm})$ and doping ratios (TNATA:NDP2 between 10:1 to 30:1). 


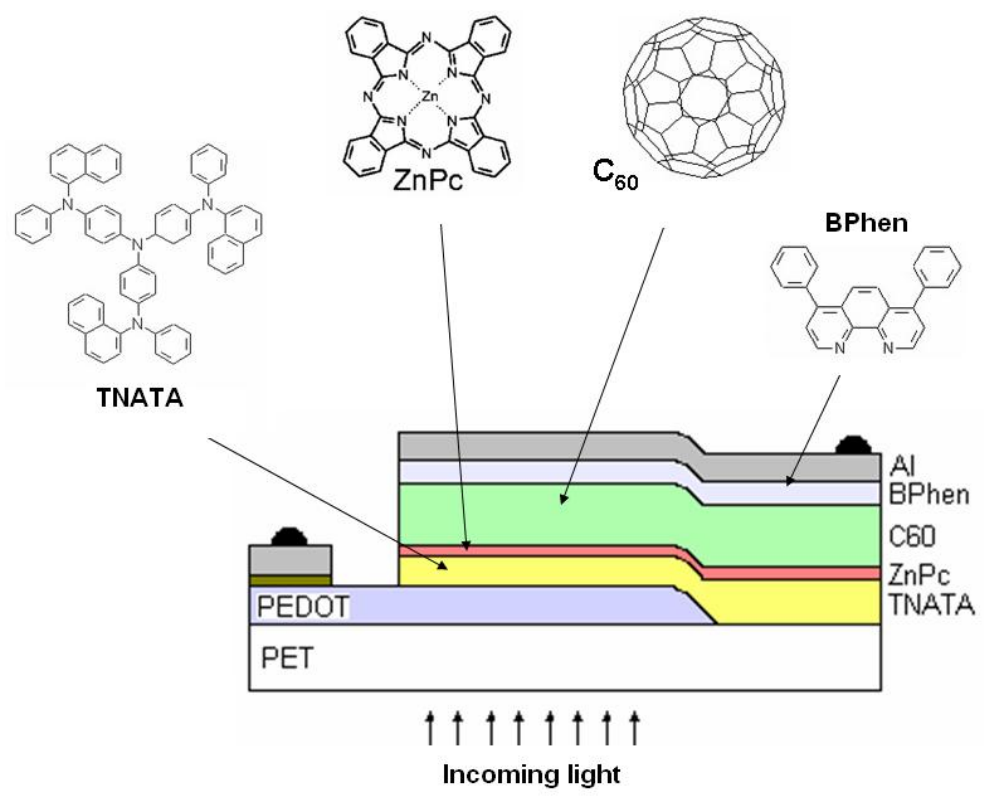

Figure 4. Structures of the used organic materials and schematic of a solar cell stack; shown is an example of a flat heterojunction of $\mathrm{ZnPc}$ and $\mathrm{C}_{60}$.

For light absorption, two different absorber structures were used:

i) zinc phthalocyanine $(\mathrm{ZnPc})(10 \mathrm{~nm})$ followed by $40 \mathrm{~nm}-50 \mathrm{~nm}$ of $\mathrm{C}_{60}$

ii) $\mathrm{ZnPc}(10 \mathrm{~nm})$ followed by co-evaporated $\mathrm{ZnPc}_{6} \mathrm{C}_{60}\left(25 \mathrm{~nm}\right.$, ratio 1:1) followed by $40 \mathrm{~nm}$ of $\mathrm{C}_{60}$

In both cases, the $40 \mathrm{~nm} \mathrm{C}_{60}$ served as absorber, but also as interface for exciton dissociation and as ETL. After the fullerene, $7 \mathrm{~nm}$ of 4,7-diphenyl-1,10-phenanthroline (BPhen) was deposited as EBL and as protective layer for the organic stack underneath to prevent damage from impinging metal atoms and to hinder metal atom diffusion into the $\mathrm{C}_{60}$. Metal top contacts were typically $80-100 \mathrm{~nm} \mathrm{Al}$, deposited at higher rates $(5-10 \AA / \mathrm{s})$ than the organic materials.

\subsection{Characterization}

Typical areas of finished solar cells ranged from $\approx 4-7 \mathrm{~mm}^{2}$, measured for every single cell using a light microscope. The solar cells were stored in air; for characterization and evaluation, they were transferred to a nitrogen glovebox. I(V)-spectra were recorded using a source measurement unit $236 \mathrm{SMU}$ (Keithley) under an AM 1.5g sun simulator (Hoenle AG) (monitored by Si photodiode; no mismatch correction). Typical light intensities were around $105 \mathrm{~mW} / \mathrm{cm}^{2}$. Reflection and transmission measurements were performed on a UV3100/MPC-3100 spectrometer (Shimadzu); the morphology of PEDOT:PSS layers was analyzed using AFM (Digital Instruments). Work function measurements were performed in a X-ray/ultraviolet photoelectron spectroscopy system (Specs) in UHV conditions. 


\section{RESULTS}

\subsection{PEDOT:PSS}

PEDOT:PSS layers on glass and on plastic foil were studied using AFM to gain insight about the surface roughness. Typical images are shown below. There was no difference found between glass and PET foil substrates; root mean square roughness of the $100 \mathrm{~nm}$ thick PEDOT:PSS layers was below $2-3 \mathrm{~nm}$ at all investigated spots, indicating a smooth surface with peaks below $20 \mathrm{~nm}$ height.
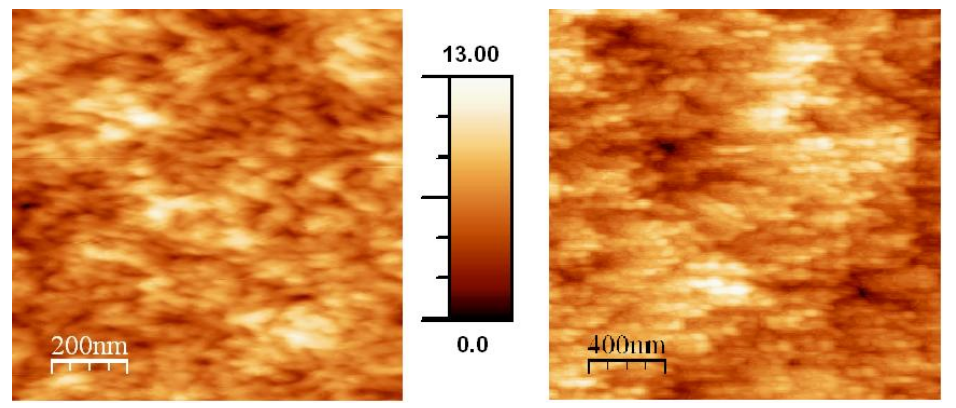

Figure 5. AFM images of PEDOT:PSS films. Left: on glass, area: $1 \mu m^{2}$; right: on PET foil, area: $4 \mu m^{2}$. Z-scale is the same for both images.

The work function of polymer films was determined by UPS. The work function of untreated PEDOT:PSS was found to be $5.05 \mathrm{eV}$. This is in very good agreements with values in the literature, which typically range from $5.0-5.2 \mathrm{eV}$, depending on the formulation, residual water content, or UV treatment. ${ }^{19}$ After addition of $10 \mathrm{wt} \%$ perfluotinated ion-exchange resin, the work function could be increased to $5.44 \mathrm{eV}$, which may be promising for future experiments with different organic materials with higher work functions.

Reflection and transmission of untreated PEDOT:PSS and of PEDOT:PSS spincoated after addition of Nafion to the solution are shown in fig. 6. Transmission is between $70-80 \%$ in the visible range. Reflection is well below 10\%, with untreated PEDOT:PSS having higher reflection and transmission than PEDOT:PSS$5 \%$ DMSO-10 wt\% Nafion. Future experiments will show the influence on solar cell performance, as has been done for OLEDs with modified PEDOT:PSS-coated ITO anodes. ${ }^{20}$
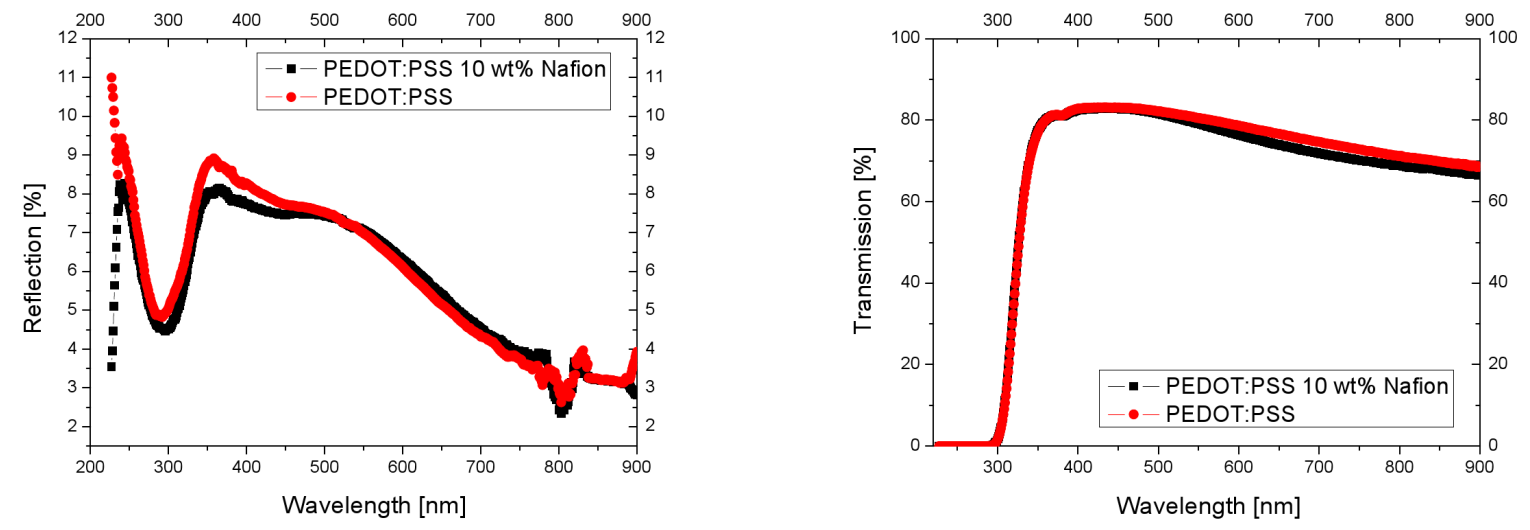

Figure 6. Left: Reflection of PEDOT:PSS/10 wt\% Nafion (black squares) and PEDOT:PSS (red circles). Right: Transmission of PEDOT:PSS/10 wt\% Nafion (black squares) and PEDOT:PSS (red circles). 


\subsection{Solar Cells}

The fabricated solar cells will be described in the form of four examples, two flat and two bulk heterojunction solar cells on glass and on PET foil, respectively. The structures are summarized in Table 1.

Table 1. Overview of presented solar cell configurations. In all cases, $7 \mathrm{~nm}$ BPhen (EBL) and $100 \mathrm{~nm} \mathrm{Al} \mathrm{(back}$ contact) were used.

\begin{tabular}{|c|c|c|c|}
\hline Designation & Substrate & HTL & Absorber thickness in $\mathrm{nm}$ \\
\hline a) flat glass & glass & $100 \mathrm{~nm}$ TNATA:NDP2 (30:1) & $\mathrm{ZnPc}(10) / \mathrm{C}_{60}(40)$ \\
\hline b) flat PET & $\mathrm{PET}$ & $100 \mathrm{~nm}$ TNATA:NDP2 (30:1) & $\mathrm{ZnPc}(10) / \mathrm{C}_{60}(40)$ \\
\hline c) bulk glass & glass & $60 \mathrm{~nm}$ TNATA:NDP2 (16:1) & $\mathrm{ZnPc}(11) / \mathrm{ZnPc} \mathrm{C}_{60}(10,1: 1) / \mathrm{C}_{60}(50)$ \\
\hline d) bulk PET & $\mathrm{PET}$ & $60 \mathrm{~nm}$ TNATA:NDP2 (11:1) & $\mathrm{ZnPc}(12) / \mathrm{ZnPc}: \mathrm{C}_{60}(25,1: 1) / \mathrm{C}_{60}(40)$ \\
\hline
\end{tabular}

The flat heterojunction solar cells are shown in fig. 7a. It is obvious that the solar cells both on glass and on PET suffer from low fill factor (FF) and high series resistance, limiting efficiencies to $0.43 \%$ and $0.18 \%$ for glass and PET, respectively. The HTLs have a high thickness of $100 \mathrm{~nm}$ since it was at first not clear if the structuring methods lead to high steps (height differences) from substrate to anode. In this case, the TNATA layers would have served as smoothing layers.

After this successful proof of principle, the HTL layer was reduced in thickness to decrease the length of the pathway for holes between donor/acceptor interface and anode; at the same time, the doping ratio TNATA:NDP2 was increased. To improve absorption while at the same time maintaining good exciton dissociation, a large interface in the form of a blend layer of $\mathrm{ZnPc}$ and $\mathrm{C}_{60}$ was introduced, supported by optical simulations to improve the distribution of the internal optical field within the solar cell stack.
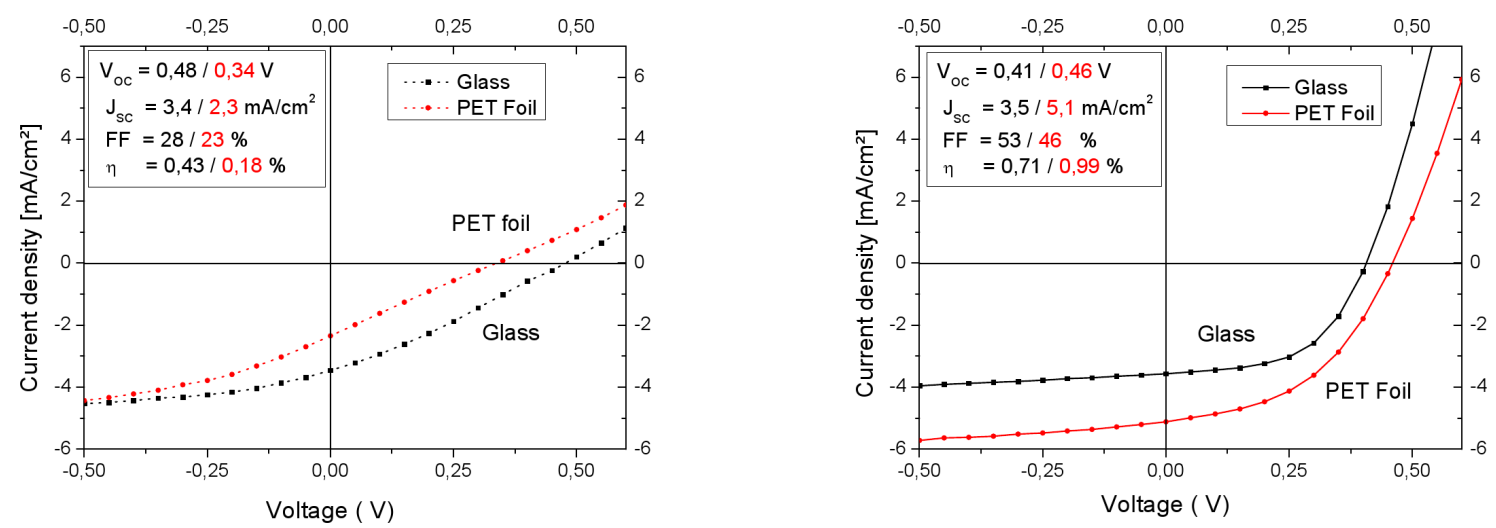

Figure 7. $J(V)$ curves of solar cells with PEDOT:PSS as hole contact.

a) left: flat heterojunction cells on glass (black squares) and PET (red circles).

b) right: bulk heterojunction cells on glass (black squares) and PET foil (red circles).

In Fig. $7 \mathrm{~b}$ it is obvious that these changes strongly influenced the FF, roughly doubling it from $28 \%$ to $53 \%$ on glass and from $24 \%$ to $46 \%$ on PET foil. The short-circuit current $J_{S C}$ remained almost constant on the glass samples, but more than doubled on PET foils from $2.3 \mathrm{~mA} / \mathrm{cm}^{2}$ to $5.1 \mathrm{~mA} / \mathrm{cm}^{2}$. We attribute this mainly to the higher thickness of the heterojunction absorber layer (solar cell c):10 nm blend; solar cell d): $25 \mathrm{~nm}$ blend). the maxima of the optical field within the stack should be close to the $\mathrm{ZnPc} / \mathrm{ZnPc}_{6} \mathrm{C}_{60}$ interface for both cases. The thicker blend layer of d) provides a higher dissociation interface while being in closer proximity to the electron collecting back contact, and at the same time increases the number of photogenerated excitons, thus leading to the highest $J_{S C}$. 
The deviations of the open-circuit voltage $V_{O C}$ cannot be explained at the moment. One would expect a correlation of $V_{O C}$ and the heterojunction type; for $\mathrm{ZnPc} / \mathrm{C}_{60}$ junctions, flat or bulk, voltages of well over $0.6 \mathrm{~V}$ were achieved in our group when using ITO substrates (without PEDOT:PSS modifications). The solar cells shown in this paper exhibit no clear systematics, especially with cell $b$ having extremely poor performance and a voltage of only $0.34 \mathrm{~V}$. Possible factors for low performance may be degradation induced by residual water in the PEDOT:PSS layer or oxygen contamination before measurement. In the case of PET foil as substrate, it is noteworthy that the foil is not sealed against water or oxygen from air, and UV light may penetrate through the foil into the organic layers. More studies are desirable to investigate the influence of HTL thickness and doping ratio, absorber stack and PEDOT:PSS treatment on the solar cell performance.

\section{CONCLUSION AND OUTLOOK}

In the current work, the first small-molecule organic solar cells on glass and PET foil are shown where ITO was successfully replaced with a stand-alone all-organic anode, PEDOT:PSS. The challenge of creating and structuring these anodes is explained; it is described how the PEDOT:PSS is structured on glass (with a polystyrene-containing solution as passivation layer) and plastic (by utilizing laser printer toner to selectively remove excess PEDOT:PSS) substrates.

Going one step further, the structured hole contacts are characterized by AFM, XPS/UPS, and spectrometer (100 nm thick, rms roughness $<3 \mathrm{~nm}, 70 \%-80 \%$ transmission in the visible range, work function of $5.05-5.44 \mathrm{eV}$, depending on additional modifications) and then used for the fabrication of prototype solar cells. First operational solar cells on both different substrates were fabricated, with efficiencies close to $1 \%$, having fill factors of over $50 \%$, short-circuit currents of over $5 \mathrm{~mA} / \mathrm{cm}^{2}$, and open-circuit voltages of up to $0.48 \mathrm{~V}$ (depending on the solar cell stack and substrate type).

It is encouraging that PEDOT:PSS is feasible as transparent electrode material, but many open questions remain. The final potential of PEDOT:PSS for SM-OSOLs remains to be tested in further studies. Approaches for optimization may include

- spincoating and outgassing in nitrogen atmosphere (glovebox) to exclude water contamination,

- structuring without involving toluene; possibly printing,

- finding the optimal stack, taking the field distribution into consideration.

Furthermore, far beyond the scope of the current work, SM-OSOLs may profit greatly from new, highperformance transporting ${ }^{21}$ or absorber ${ }^{22}$ materials or novel heterojunction morphology ${ }^{23}$ providing exciting challenges for further research.

\section{ACKNOWLEDGMENTS}

I want to thank Selina Olthof (IAPP, TU Dresden) for support with XPS and UPS measurements, Nikola Allinger (IAPP, TU Dresden) for help with reflection and transmission measurements and Dr. W. Lövenich and Dr. A. Elschner from H.C. Starck GmbH for providing PEDOT:PSS. The current work is supported by the Bundesministerium für Bildung und Forschung in the framework of the InnoProfile project (03IP602).

\section{REFERENCES}

[1] The Intergovernmental Panel on Climate Change; Assessment Reports, Special Reports, Methodology Reports, Technical Papers and Supporting Material are available online at http://www.ipcc.ch/

[2] B. P. Rand, J. Genoe, P. Heremans, and J. Poortmans, Solar Cells Utilizing Small Molecular Weight Organic Semiconductors, Prog. Photovolt: Res. Appl. 15, 659-676 (2007)

[3] B. O'Regan and M. Graetzel, A low-cost, high-efficiency solar cell based on dye-sensitized colloidal $\mathrm{TiO}_{2}$ films, Nature 353, 737-739 (1991)

[4] D. J. Milliron, I. Gur and A. P. Alivisatos, Hybrid Organic-Nanocrystal Solar Cells, MRS Bulletin 30(1), 41-44 (2005) 
[5] G. Dennler and N. S. Sariciftci, Flexible conjugated polymer-based plastic solar cells: from basics to applications, Proceedings of the IEEE 98(3), 1429-1439 (2005)

[6] C. W. Tang, Two-layer organic photovoltaic cell, Appl. Phys. Lett. 48(2), 183-185 (1986)

[7] K. Walzer, B. Maennig, M. Pfeiffer, and K. Leo, Highly Efficient Organic Devices Based on Electrically Doped Transport Layers, Chemical Reviews 107(4), 1233-1271 (2007)

[8] B. Maennig, J. Drechsel, D. Gebeyehu, P. Simon, F. Kozlowski, A.Werner, F. Li, S. Grundmann, S. Sonntag, M. Koch, K. Leo, M. Pfeiffer, H. Hoppe, D. Meissner, N. S. Sariciftci, I. Riedel, V. Dyakonov, and J. Parisi, Organic p-i-n solar cells, Appl. Phys. A-Mater. 79, 1-14 (2004)

[9] J. Xue, S. Uchida, B. P. Rand, and S. R. Forrest, Asymmetric tandem organic photovoltaic cells with hybrid planar-mixed molecular heterojunctions, Appl. Phys. Lett. 85, 5757-5759 (2004)

[10] K. Schulze, C. Uhrich, R. Schueppel, K. Leo, M. Pfeiffer, E. Brier, E. Reinhold, and P. Baeuerle, Organic solar cells on indium tin oxide and aluminium doped zinc oxide anodes, Appl. Phys. Lett. 91, 073521-073523 (2007)

[11] M. Glatthaar, M. Niggemann, B. Zimmermann, P. Lewer, M. Riede, A. Hinsch and J. Luther, Organic solar cells using inverted layer sequence, Thin Solid Films 491(1-2), 298-300 (2005)

[12] J. Huang, P. F. Miller, J. C. de Mello, A. J. de Mello, and D. D. C. Bradley, Influence of thermal treatment on the conductivity and morphology of PEDOT/PSS films, Synthetic Metals 139, 569-572 (2003)

[13] B. Zimmermann, M. Glatthaar, M. Niggemann, M. K. Riede, A. Hinsch, and A. Gombert, ITO-free anode wrap through organic solar cells - a module concept for cost efficient reel to reel production, Sol. En. Mat. Sol. Cells 91, 374-378 (2007)

[14] K. Tvingstedt, and O. Inganaes, Electrode Grids for ITO-free Organic Photovoltaic Devices, Adv. Mater. 19(19), 2893-2897 (2007)

[15] K. Fehse, K. Walzer, K. Leo, W. Loevenich and A. Elschner, Highly Conductive Polymer Anodes as Replacements for Inorganic Materials in High-Efficiency Organic Light-Emitting Diodes, Adv. Mater. 19, 441-444 (2007)

[16] J. Meiss, N. Allinger, M. K. Riede, and K. Leo, Improved light harvesting in ITO-free inverted bulk heterojunction organic solar cells using capping layers, submitted

[17] J. van de Lagemaat, T. M. Barnes, G. Rumbles, S. E. Shaneen, T. J. Coutts, C. Weeks, I. Levitsky, J. Peltola, and P. Glatkowsky, Organic solar cells with carbon nanotubes replacing $\operatorname{In}_{2} \mathrm{O}_{3}: \mathrm{Sn}$ as the transparent electrode, Appl. Phys. Lett. 88, 233503-233505 (2006)

[18] M. W. Rowell, M. A. Topinka, M. D. McGehee, H.-J. Prall, G. Dennler, N. S. Sariciftci, L. Hu, and G. Gruner, Organic solar cells with carbon nanotube network electrodes, Appl. Phys. Lett. 88, 233506-233508 (2006)

[19] C. Tengstedt, A. Kanciurzewska, M. P. de Jong, S. Braun, W. R. Salaneck, and Mats Fahlman, Ultraviolet light-ozone treatment of poly(3,4-ethylenedioxy-thiophene)-based materials resulting in increased work functions, Thin Solid Films 515, 2085-2090 (2006)

[20] T.-W. Lee, O. Kwon, M.-G. Kim, S. H. Park, J. Chung, S. Y. Kim, Y. Chung, J.-Y. Park, E. Han, D. H. Huh, J.-J. Park, and L. Pu, Hole-injecting conducting-polymer compositions for highly efficient and stable organic light-emitting diodes, Appl. Phys. Lett. 87, 231106 (2005)

[21] S. Pfuetzner, A. Petrich, C. Malbrich, J. Meiss, M. Koch, M. K. Riede, M. Pfeiffer, K. Leo, Characterisation of different hole transport materials as used in organic p-i-n solar cells, Proceedings of SPIE, submitted

[22] K. Schulze, C. L. Uhrich, R. Schueppel, K. Leo, M. Pfeiffer, E. Brier, E. Reinold, and P. Baeuerle, Efficient Vacuum-Deposited Organic Solar Cells Based on a New Low-Bandgap Oligothiophene and Fullerene $\mathrm{C}_{60}$, Adv. Mater. 18, 2872-2875 (2006)

[23] F. Yang, K. Sun, and S. R. Forrest, Efficient Solar Cells Using All-Organic Nanocrystalline Networks, Adv. Mater. 19, 4166-4171 (2007) 